\title{
Long-term outcomes of coronary artery bypass grafting patients supported preoperatively with an intra-aortic balloon pump
}

\author{
Eli Hemo, MD, ${ }^{\text {a }}$ Benjamin Medalion, MD, ${ }^{\text {b,c }}$ Rephael Mohr, MD, ${ }^{\text {a,c }}$ Yossi Paz, MD,,${ }^{\text {a,c }}$ \\ Amir Kramer, MD, PhD, ${ }^{\mathrm{a}, \mathrm{c}}$ Gideon Uretzky, MD, ${ }^{\mathrm{a}, \mathrm{c}}$ Nachum Nesher, MD, ${ }^{\mathrm{a}, \mathrm{c}}$ and Dmitri Pevni, MD ${ }^{\mathrm{a}, \mathrm{c}}$
}

Objective: Most studies describing the outcome of coronary artery bypass grafting patients supported preoperatively with an intra-aortic balloon pump (IABP) have reported early results. The purpose of our study was to evaluate the early and long-term results.

Methods: Of 2658 isolated coronary artery bypass grafting procedures performed from 1996 to 2001, 215 were supported preoperatively with an IABP. The indications for IABP insertion were cardiogenic shock in 18 $(8.4 \%)$, acute evolving myocardial infarction in $38(17.7 \%)$, clinical instability in $84(39.1 \%)$, and critical coronary lesions in $75(34.9 \%)$.

Results: Operative mortality was $12.6 \%$. The mortality of the cardiogenic shock patients was greater $(22.2 \%$; $P=.174$ ). Logistic regression analysis showed patient age (odds ratio, $1.057 ; 95 \%$ confidence interval, 1.010-1.108) and cardiopulmonary bypass (CPB) time (odds ratio, 1.020; 95\% confidence interval, 1.008-1.031) were associated with increased operative mortality. An increased number of bypass grafts had a protective effect (odds ratio, $0.241 ; 95 \%$ confidence interval, $0.113-0.515$ ). The actual early mortality was lower than the logistic EuroSCORE calculated mortality $(12.6 \%$ vs $32.8 \%, P<.0001)$. The mean follow-up was $8 \pm 4$ years. The Kaplan-Meier 10-year survival was $49 \%$. The Cox adjusted overall (early and late) survival and major adverse cardiac events-free survival of the different IABP subgroups was similar. Cox analyses showed peripheral vascular disease, off-pump coronary artery bypass surgery, age, CPB time, female gender, and fewer bypass grafts were associated with decreased survival.

Conclusions: In patients supported preoperatively with an IABP, better early and long-term results were strongly related to younger age, a shorter CPB time, and a greater number of bypass grafts. Avoiding the use of CPB (off pump) in these emergency cases is not recommended. (J Thorac Cardiovasc Surg 2014;148:1869-75)

Several clinical studies have demonstrated improved outcome with insertion of an intra-aortic balloon pump (IABP) before surgery. ${ }^{1,2}$ However, other clinical studies have failed to detect a significant difference in outcomes with the use of a preoperative IABP. ${ }^{3,4}$ The greater rates of IABP-related complications observed in the past have dissuaded some surgeons from routine preoperative use of IABP in high-risk patients. ${ }^{4}$

The introduction of new IABP guidewires and technological improvements in catheter size and software have reduced the occurrence of complications ${ }^{5}$ and have expanded the indications for preoperative IABP use. ${ }^{6}$

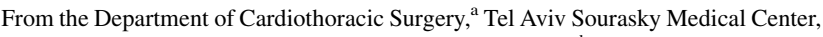
Tel Aviv, Israel; Department of Cardiothoracic Surgery, ${ }^{\mathrm{b}}$ Rabin Medical Center, Petach Tiqva, Israel; and Sackler School of Medicine, ${ }^{\mathrm{c}}$ Tel Aviv University, Tel Aviv, Israel.

Disclosures: Authors have nothing to disclose with regard to commercial support.

Drs Nesher and Pevni contributed equally to this work.

Received for publication June 28, 2013; revisions received Nov 13, 2013; accepted for publication Dec 5, 2013; available ahead of print Feb 9, 2014.

Address for reprints: Rephael Mohr, MD, Department of Cardiothoracic Surgery, Tel Aviv Sourasky Medical Center, 6 Weizman St, Tel Aviv 64239, Israel (E-mail: pevnid@gmail.com).

$0022-5223 / \$ 36.00$

Copyright (c) 2014 by The American Association for Thoracic Surgery

http://dx.doi.org/10.1016/j.jtcvs.2013.12.063
}

Most studies describing the outcome of high-risk coronary patients who have undergone surgery with preoperative IABP support have reported early results. The purpose of our study was to evaluate the early and longterm $(\leq 15$ years postoperatively) results.

\section{METHODS}

Of 2658 patients undergoing isolated coronary artery bypass grafting (CABG) at Tel Aviv Medical Center from 1996 to 2001, 215 (8.1\%) were supported preoperatively with an IABP that was not removed before surgery. The preoperative and intraoperative patient data (Table 1) and the indication for IABP insertion were collected from the hospital medical records. The indications for IABP insertion were cardiogenic shock (subgroup 1) in $18(8.4 \%)$, acute evolving myocardial infarction (MI) with critical coronary stenosis (subgroup 2 ) in $38(17.7 \%)$, clinical instability (subgroup 3 ) in $84(39.1 \%$ ), and critical coronary lesions without evidence of MI (subgroup 4) in $75(34.9 \%)$. The expected operative mortality was calculated using the logistic EuroSCORE. ${ }^{7}$ Follow-up data were obtained after institutional review board approval using a telephone questionnaire and the Israeli National Registry database.

\footnotetext{
Surgical Techniques

The IABP was inserted in all patients preoperatively, in most, in the catheterization laboratory.

Surgery was performed with standard cardiopulmonary bypass (CPB) or off-pump coronary artery bypass (OPCAB). Myocardial preservation during $\mathrm{CPB}$ involved intermittent, antegrade, or antegrade plus retrograde
} 


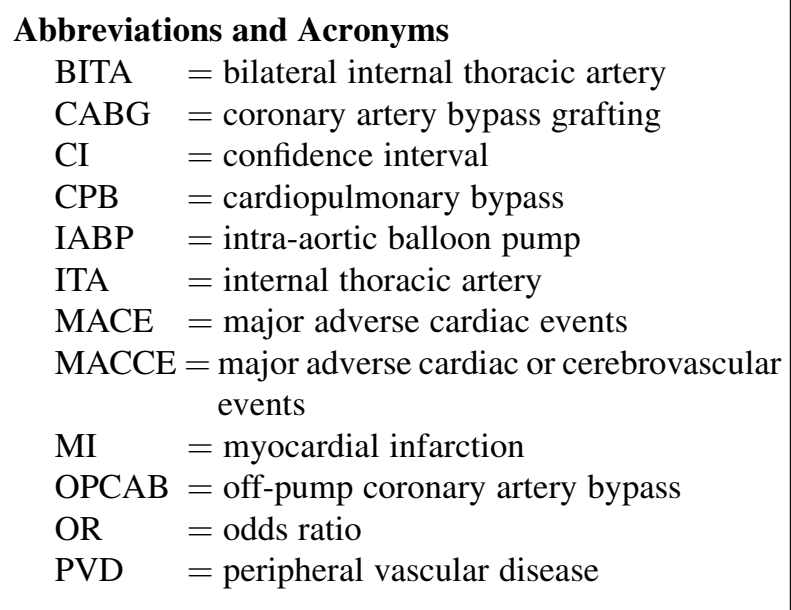

blood cardioplegia $\left(30^{\circ}-32^{\circ} \mathrm{C}\right)$. Coronary stabilization during OPCAB was facilitated with CTS stabilizers (Guidant, Cupertino, Calif) or the Octopus system (Medtronic, Minneapolis, Minn). Internal thoracic arteries (ITAs) were mobilized from the chest wall as skeletonized vessels. During the study period, in all patients undergoing bilateral ITA (BITA) grafting, BITAs were used to graft the left coronary system (ie, the myocardial territory supplied by the left anterior descending and left circumflex arteries). ${ }^{8}$

The department's strategy was to use the right ITAs, right gastroepiploic arteries, and radial arteries as grafts to the right coronary artery branches only in the presence of significant stenosis (ie, $>80 \%$ ). ${ }^{9,10}$ However, in most cases, a saphenous vein graft was the preferred conduit for right coronary artery revascularization. The surgical variables are summarized in Table 2.

To decrease the risk of spasm of the arterial grafts, we treated all our patients with a high-dose intravenous infusion of isosorbide dinitrate (Isoket, See Agis, Monheim, Germany) during the first 48 hours postoperatively. Calcium channel blockers (diltiazem 90 to $180 \mathrm{mg} / \mathrm{d}$ orally) were given to patients operated on using the right gastroepiploic artery or radial artery from the second postoperative day for $\geq 3$ months. ${ }^{8}$

\section{Definition of Terms and Data Collection}

The patient data were analyzed according to the American College of Cardiology/American Heart Association clinical data standards. ${ }^{11}$

A perioperative MI was defined by the appearance of new $\mathrm{Q}$ waves on the electrocardiogram associated with elevated levels of creatine phosphokinase-MB fraction $>50 \mathrm{mU} / \mathrm{mL}$. A cerebrovascular accident was defined as a new permanent neurologic deficit and computed tomography evidence of cerebral infarction. Chronic renal failure was diagnosed if the creatinine level was $>1.8 \mathrm{mg} / \mathrm{dL}$. Our definition of an "emergency operation" was determined using the Society of Thoracic Surgeons guidelines ${ }^{12}$ and included patients operated on within 24 hours of cardiac catheterization, with ongoing angina, failed percutaneous transluminal coronary angioplasty, acute evolving MI, pulmonary edema, and cardiogenic shock. For patients who needed emergency surgery and were not stabilized after intra-aortic balloon counterpulsation, we usually used 1 ITA combined with saphenous vein grafts. Deep sternal infection was defined as the sum of deep infection and late dehiscence requiring sternectomy. An IABP-related vascular complication was defined as an acute perfusion compromise to a limb or an organ distal to the balloon position. An early unfavorable event was defined as the occurrence in the perioperative period of either 1 of the following: acute MI, acute cerebral infarct, deep sternal infection, IABP-related vascular complications, need for revision, or death.

Major adverse cardiac events (MACE) were defined as the occurrence of cardiac-related mortality, nonfatal MI, or the need for repeat coronary revascularization. Major adverse cardiac or cerebrovascular events (MACCE) were defined as either MACE or cerebral infarct. Complete revascularization was defined as revascularization of all coronary systems with vessel stenosis $>70 \%$.

\section{Statistical Analysis}

Data are expressed as the mean \pm standard deviation or as a proportion. The chi-square test and 2-sample $t$ test was used to compare discrete and continuous variables, respectively. Multivariate logistic regression analysis was used to predict early mortality and early unfavorable events using various risk factors. The odds ratios (ORs) and $95 \%$ confidence intervals (CIs) are presented. The Cox proportional hazards model was used to evaluate the influence of perioperative and operative variables on overall (early plus late) mortality and morbidity (MACE, MACCE, and angina recurrence). We used the stepwise conditional forward selection method in all multivariate analyses; however, the IABP subgroups were forced into all models. The results of the Cox analysis are expressed as hazard ratios and $95 \%$ CIs. Postoperative survival is expressed using the Kaplan-Meier method, and the survival curves were compared using the log-rank test. The Cox model was used for coronary risk-adjusted curves. All analyses were performed with Statistical Package for Social Sciences, version 18, software (SPSS, Inc, Chicago, Ill).

\section{RESULTS}

The patients' preoperative and operative characteristics are listed in Tables 1 and 2. The mean number of grafts per patient was 2.67. Of the patients, $53(24.6 \%)$ underwent surgery without $\mathrm{CPB}(\mathrm{OPCAB})$. The average CPB time for patients treated with CPB was $94.5 \pm 39$ minutes, and the mean aortic crossclamp time was $72.0 \pm$ 25 minutes. Operative mortality (30 days postoperatively) in the cohort of 215 consecutive IABP-supported patients was $12.6 \%$. The early mortality of the patients with cardiogenic shock was $22.2 \%$ (4 of $18 ; P=.174$ compared with the other subgroups of IABP insertion indications). Operative mortality for the female patients was $19.7 \%$ (12 of 61 ; $P=.043)$ and for the patients with acute evolving MI was $17.1 \%$ (18 of $105 ; P=.037$; Table 3 ).

Multivariate logistic regression analysis revealed that operative mortality was related to CPB time $(P=.001$; OR, $1.020 ; 95 \% \mathrm{CI}, 1.008-1.031)$ and patient age $(P=.018$; OR, $1.057 ; 95 \%$ CI, 1.010-1.108). A CPB time of 70 minutes was a good threshold at which to best separate patients with good and poor outcomes. The mortality of patients with a CPB time of $\leq 70$ minutes was $6.5 \%$ versus $14 \%$ and $17 \%$ for a longer $\mathrm{CPB}$ time and $\mathrm{OPCAB}$, respectively $(P<.001)$.

The use of BITAs was associated with decreased early mortality, as expected for the BITA patients $(5.8 \%$ vs $17.1 \%$ for non-BITA patients; $P=.011$ ). However, BITA did not emerge as a significant predictor on multivariate analysis. An increased number of bypass grafts had a protective effect (OR, 0.241; 95\% CI, 0.113-0.515; $P<.001$ ).

The mean additive and logistic EuroSCORE for the entire cohort was $12 \pm 3$ and $32 \pm 2$, respectively. The actual early postoperative mortality observed in each of the IABP 
TABLE 1. Patient characteristics and overall (early and late) crude mortality*

\begin{tabular}{lcccc}
\hline \multicolumn{1}{c}{ Factor } & Prevalence $\dagger$ & $\begin{array}{c}\text { Mortality } \\
\text { with factor }\end{array}$ & $\begin{array}{c}\text { Mortality } \\
\text { without factor }\end{array}$ & $\begin{array}{c}\boldsymbol{P} \\
\text { value }\end{array}$ \\
\hline Cardiogenic shock & $18(7.9)$ & $14(77.8)$ & $106(53.8)$ & .026 \\
Female gender & $61(28.4)$ & $47(78.3)$ & $73(49.3)$ & $<.001$ \\
Age & - & $72.1 \pm 9.5$ & $63.9 \pm 11.1$ & $<.001$ \\
EuroSCORE & - & $13.5 \pm 3$ & $10.5 \pm 2.3$ & $<.001$ \\
Age $\geq 70$ y & $106(49.3)$ & $74(69.8)$ & $46(45.1)$ & $<.001$ \\
NIDDN & $53(27.5)$ & $34(64.2)$ & $86(55.5)$ & NS \\
IDDM & $8(3.7)$ & $6(75)$ & $114(57)$ & NS \\
Hypertension & $138(64.2)$ & $90(65.2)$ & $30(42.9)$ & .002 \\
COPD & $23(10.7)$ & $15(65.2)$ & $105(56.8)$ & NS \\
CHF & $32(14.9)$ & $26(81.3)$ & $94(53.4)$ & .002 \\
PVD & $42(19.5)$ & $37(88.1)$ & $83(50)$ & $<.001$ \\
CRF & $19(8.8)$ & $16(84.2)$ & $104(55)$ & .011 \\
Functional & $10(4.7)$ & $10(100)$ & $110(55.6)$ & .003 \\
$\quad$ neurologic & & & & \\
$\quad$ dysfunction & & & & \\
UAP & $181(84.2)$ & $104(57.5)$ & $16(59.3)$ & NS \\
Old MI ( $\geq 30$ d) & $61(28.4)$ & $44(72.1)$ & $76(51.7)$ & .005 \\
Acute MI $(<1$ wk) & $105(48.8)$ & $64(62.9)$ & $56(52.9)$ & NS \\
EF $\leq 35 \%$ & $40(18.6)$ & $27(67.5)$ & $93(55.4)$ & NS \\
Left main stenosis & $120(55.8)$ & $65(54.2)$ & $55(62.5)$ & NS \\
Previous PCI & $42(19.5)$ & $33(78.6)$ & $87(52.4)$ & .002 \\
3-Vessel disease & $145(67.4)$ & $90(62.1)$ & $30(47.6)$ & .037 \\
$\quad$ (vs $\leq 2-v e s s e l$ & & & & \\
disease) & & & & \\
\hline
\end{tabular}

Data presented as $\mathrm{n}(\%)$ or mean \pm standard deviation. NIDDM, Noninsulindependent diabetes mellitus; $N S$, not significant; IDDM, insulin-dependent diabetes mellitus; $C O P D$, chronic obstructive pulmonary disease; $C H F$, congestive heart failure; $P V D$, peripheral vascular disease; $C R F$, chronic renal failure; $U A P$, unstable angina pectoris; $M I$, myocardial infarction; $E F$, ejection fraction; $P C I$, percutaneous coronary intervention. *Number of deaths/number of patients in the subgroup with long-term follow-up data. †Number of patients in the subgroup/215 patients.

indication subgroups and in the entire cohort was lower than the logistic EuroSCORE calculated mortality (Table 4).

A total of $4(1.9 \%)$ perioperative MIs, $4(1.9 \%)$ sternal wound infections, $15(7 \%)$ cerebral infarctions, $13(6 \%)$ IABP-related vascular complications, and $10(4.7 \%)$ revisions occurred. An increased risk (univariate) of

TABLE 2. Patient operative data and overall crude mortality*

\begin{tabular}{lcccc}
\hline \multicolumn{1}{c}{ Factor } & Prevalence $\dagger$ & $\begin{array}{c}\text { Mortality } \\
\text { with factor }\end{array}$ & $\begin{array}{c}\text { Mortality } \\
\text { without factor }\end{array}$ & $\begin{array}{c}\boldsymbol{P} \\
\text { value }\end{array}$ \\
\hline Repeat operation & $15(7.0)$ & $13(86.7)$ & $107(55.4)$ & .015 \\
BITA & $86(40)$ & $36(42.9)$ & $84(67.7)$ & $<.001$ \\
SVG & $112(52.1)$ & $66(58.9)$ & $54(56.3)$ & NS \\
RGEA & $6(2.8)$ & $3(50)$ & $117(57.9)$ & NS \\
Bypass to RCA & $114(53.0)$ & $59(51.8)$ & $61(64.9)$ & .038 \\
OPCAB & $53(24.6)$ & $41(77.4)$ & $79(51)$ & .001 \\
CPB time (min) & - & $66.3 \pm 60.9$ & $76.6 \pm 41.5$ & NS \\
\hline
\end{tabular}

Data presented as $\mathrm{n}(\%)$ or mean \pm standard deviation. BITA, Bilateral internal thoracic artery; $S V G$, saphenous vein graft; $N S$, not significant; $R G E A$, right gastroepiploic artery; $R C A$, right coronary artery; $O P C A B$, off-pump coronary artery bypass; $C P B$, cardiopulmonary bypass. *Number of deaths/number of patients in the subgroup with long-term follow-up data. †Number of patients in the subgroup/ 215 patients.
TABLE 3. IABP and early mortality

\begin{tabular}{lcccc}
\hline \multicolumn{1}{c}{ Factor } & Prevalence* & $\begin{array}{c}\text { Mortality } \\
\text { with factor }\end{array}$ & $\begin{array}{c}\text { Mortality } \\
\text { without factor }\end{array}$ & $\boldsymbol{P}$ value \\
\hline Female gender & $61(28.4)$ & $12(19.7)$ & $15(9.7)$ & .043 \\
Acute MI & $105(48.8)$ & $18(17)$ & $9(8.2)$ & .037 \\
Recent MI & $113(52.6)$ & $19(16.8)$ & $8(7.8)$ & .037 \\
BITA & $86(40.0)$ & $5(5.8)$ & $22(17.1)$ & .011 \\
Single bypass & $29(13.5)$ & $10(34.5)$ & $17(9.1)$ & .001 \\
Cardiogenic & $18(8.4)$ & $4(22.2)$ & $23(11.7)$ & NS \\
$\quad$ shock & & & & \\
Subgroup 2 & $38(17.7)$ & $6.15(8)$ & $21(11.9)$ & NS \\
Subgroup 3 & $84(39.1)$ & $14(16.7)$ & $13(10.9)$ & NS \\
Subgroup 4 & $75(34.9)$ & $3(4)$ & $24(17.1)$ & NS \\
Age $\leq 70$ y & $106(49.3)$ & $15(14.1)$ & $12(11)$ & NS \\
NIDDM & $53(27.5)$ & $4(7.5)$ & $23(14)$ & NS \\
IDDM & $8(3.7)$ & $1(12.5)$ & $26(12.5)$ & NS \\
Hypertension & $138(64.2)$ & $16(11.5)$ & $11(14.3)$ & NS \\
COPD & $23(10.7)$ & $4(17.4)$ & $23(12)$ & NS \\
CHF & $32(14.9)$ & $5(15.6)$ & $22(12)$ & NS \\
PVD & $42(19.5)$ & $6(14.2)$ & $21(12.1)$ & NS \\
CRF & $19(8.8)$ & $4(21)$ & $23(11.7)$ & NS \\
Neurologic & $10(4.7)$ & $1(10)$ & $26(12.7)$ & NS \\
$\quad$ dysfunction & & & & \\
Old MI & $61(28.4)$ & $8(13.1)$ & $19(9.1)$ & NS \\
EF $\geq 35 \%$ & $40(18.6)$ & $8(20)$ & $19(10.8)$ & NS \\
Left main artery & $120(55.8)$ & $12(10)$ & $15(15.8)$ & NS \\
Previous PCI & $42(19.5)$ & $7(16)$ & $20(10.8)$ & NS \\
3VD vs $\leq 2$ VD & $145(67.4)$ & $17(1.7)$ & $10(14.2)$ & NS \\
\hline Datesen & & & & \\
\hline
\end{tabular}

Data presented as n (\%). IABP, Intra-aortic balloon pump; $M I$, myocardial infarction; BITA, bilateral internal thoracic artery; Subgroup 2, evolving MI (24 h); Subgroup 3, clinical instability; Subgroup 4, critical coronary lesions; NIDDM, noninsulindependent diabetes mellitus; IDDM, insulin-dependent diabetes mellitus; $C O P D$, chronic obstructive pulmonary disease; $C H F$, congestive heart failure; $P V D$, peripheral vascular disease; $C R F$, chronic renal failure; $E F$, ejection fraction; $P C I$, percutaneous coronary intervention; $V D$, vessel disease; $N S$, not significant. *Number of patients in the subgroup/215 patients.

perioperative cerebral infarctions was found among patients $\geq 70$ years (12 of $106,11.3 \%$ ), patients with insulin-dependent diabetes mellitus ( 4 of $8,50 \%$ ), and patients with peripheral vascular disease (PVD) (6 of 42, $14.3 \%)$. IABP-related vascular complications were more common among patients with PVD $(14.3 \%)$, acute MI $(9.5 \%)$, and old MI (11.3\%).

TABLE 4. Observed early mortality and logistic EuroSCORE expected early mortality

\begin{tabular}{lccc}
\hline \multicolumn{1}{c}{ Group } & $\begin{array}{c}\text { EuroSCORE } \\
\text { expected mortality }\end{array}$ & $\begin{array}{c}\text { Observed } \\
\text { mortality }\end{array}$ & $\begin{array}{c}\boldsymbol{P} \\
\text { value }\end{array}$ \\
\hline Subgroup 1 $(\mathrm{n}=18)$ & $8(43.5)$ & $4(22.2)$ & .174 \\
Subgroup 2 $(\mathrm{n}=38)$ & $12(32.3)$ & $6(15.6)$ & .092 \\
Subgroup 3 $(\mathrm{n}=84)$ & $33(38.9)$ & $14(16.7)$ & .001 \\
Subgroup 4 $(\mathrm{n}=75)$ & $18(23.6)$ & $3(4.0)$ & .0005 \\
Total $(\mathrm{n}=215)$ & $70(32.8)$ & $27(12.6)$ & $<.00001$ \\
\hline
\end{tabular}

Data presented as $\mathrm{n}(\%)$. Subgroup 1, Cardiogenic shock; Subgroup 2, evolving myocardial infarction (24 h); Subgroup 3, clinical instability; Subgroup 4, critical coronary lesions. 


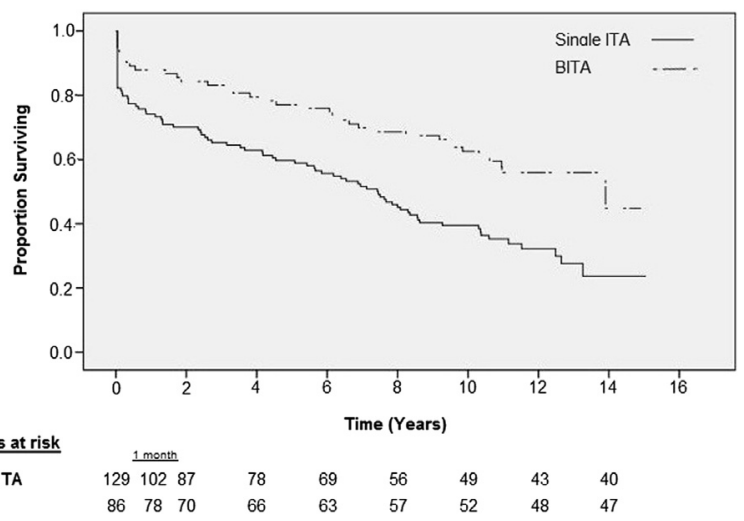

FIGURE 1. Survival curves (Kaplan-Meier) of single internal thoracic artery (ITA) versus bilateral ITA (BITA) grafting.

Follow-up data for 1 to 180 months postoperatively (mean, $8 \pm 4$ years) was available for $95.7 \%$ of the surviving patients (180 of 188); 93 late deaths occurred. The 10-year actuarial survival (Kaplan-Meier) was $48.7 \% \pm 3.5 \%$. The 10-year survival of female patients was $31.7 \% \pm 6 \%$ compared with $58.3 \% \pm 6 \%$ for the male patients $(P<.001, \log$-rank test $)$. The 10 -year survival of patients with PVD was $21.4 \% \pm 6.3 \%$ compared with $58.8 \% \pm$ $6.8 \%$ for those without PVD $(P<.001)$, that of the OPCAB patients $(23.6 \% \pm 6 \%$ vs $67.4 \% \pm 7.2 \% ; P<$ .001 CPB patients), and that of the cardiogenic shock subgroup was $35.3 \% \pm 11.6 \%$. The survival of the cardiogenic shock subgroup was significantly lower than the survival of the other 3 subgroups $(56.6 \% \pm 8.2 \%, 42 \% \pm 5.5 \%$, $55.4 \% \pm 5.9 \%$ for subgroups 2,3 and 4 respectively; $P=.049$ ). The 10 -year survival of BITA patients was significantly better than that of patients treated using a single ITA $(62.6 \% \pm 5.3 \%$ vs $39.5 \% \pm 4.4 \% ; P<.001$; Figure 1$)$.

The relationship between the preoperative and operative patient characteristics and "crude" overall mortality rate estimates (ie, the number of dead divided by the total number of patients in the subgroup) is demonstrated in Tables 1 and 2.

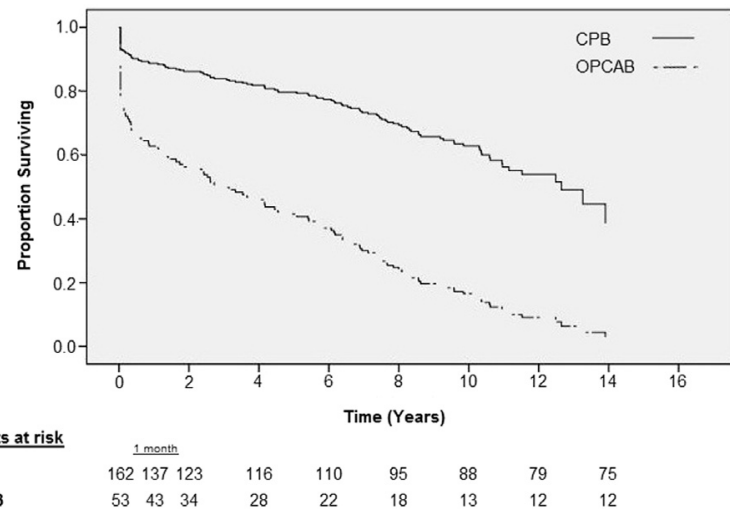

FIGURE 2. Cox-adjusted survival of off-pump coronary artery bypass $(O P C A B)$ versus cardiopulmonary bypass $(C P B)$ patients.

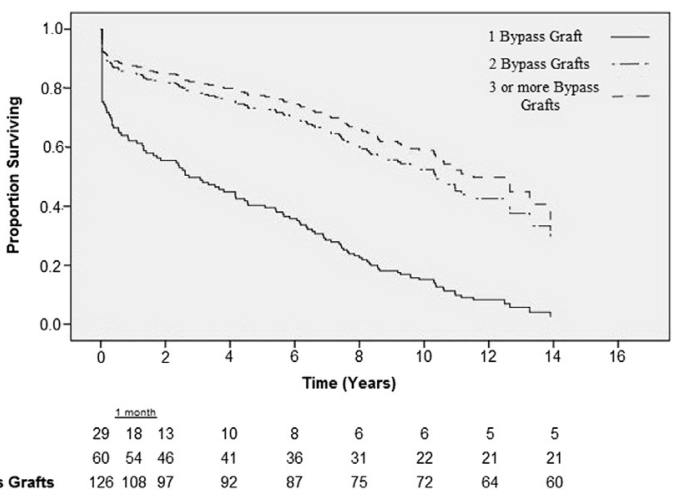

FIGURE 3. Relation between long-term Cox-adjusted survival and the number of bypass grafts performed.

The Cox-adjusted overall (early and late) survival and MACE- and MACCE-free survival of the different IABP subgroups were similar.

The Cox analyses showed that PVD, OPCAB (Figure 2), age, CPB time, and female gender were associated with increased overall mortality. On the other hand, a greater number of bypass grafts improved overall survival (Figure 3 and Table 5).

Diabetes mellitus, repeat operation, OPCAB, and an increased CPB time were predictors of shorter MACEand MACCE-free survival. An additional predictor of

TABLE 5. Cox proportional hazards model for total mortality and long-term morbidity

\begin{tabular}{lllr}
\hline \multicolumn{1}{c}{ Variable } & HR & $\mathbf{9 5} \% \mathbf{C I}$ & $\boldsymbol{P}$ value \\
\hline Total mortality & & & \\
PVD & 2.508 & $1.657-3.794$ & $<.001$ \\
OPCAB & 3.877 & $1.962-7.660$ & $<.001$ \\
Age & 1.040 & $1.020-1.061$ & $<.001$ \\
CPB time & 1.012 & $1.006-1.018$ & $<.001$ \\
Bypass graft number & 0.650 & $0.490-0.863$ & .003 \\
Female gender & 1.580 & $1.054-2.369$ & .027 \\
MACE & & & \\
OPCAB & 4.732 & $1.843-12.154$ & .001 \\
DM & 2.259 & $1.356-3.763$ & .002 \\
Repeat operation & 3.134 & $1.470-6.684$ & .003 \\
CPB time & 1.011 & $1.002-1.019$ & .011 \\
HTN & 1.869 & $1.056-3.306$ & .032 \\
MACCE & & & \\
OPCAB & 6.205 & $2.340-16.453$ & $<.001$ \\
DM & 2.045 & $1.277-3.273$ & .003 \\
PVD & 2.073 & $1.228-3.501$ & .006 \\
Old MI & 1.832 & $1.165-2.881$ & .009 \\
CPB time & 1.012 & $1.003-1.020$ & .010 \\
Repeat operation & 2.394 & $1.142-5.020$ & .021 \\
\hline$H R$, Hazard ratio; $C I$, confidence interval; $P V D$, peripheral vascular disease; $O P C A B$, \\
off-pump coronary artery bypass; $C P B$, cardiopulmonary bypass; $M A C E$, major \\
adverse cardiac events; $D M$, diabetes mellitus; $H T N$, hypertension; $M A C C E$, major \\
adverse cardiac or cerebrovascular events; $M I$, myocardial infarction; $P V D$, periph- \\
eral vascular disease. & & & \\
& & &
\end{tabular}


reduced MACE-free survival was hypertension, and additional predictors of reduced MACCE-free survival were old MI and PVD (Table 5).

When the logistic EuroSCORE was forced into the Cox model, it was an independent and a strong predictor of MACE and MACCE (hazard ratio, 1.022; 95\% CI, 1.010$1.034 ; P<.001$; and hazard ratio, $1.019 ; 95 \% \mathrm{CI}, 1.007$ $1.030 ; P=.001$, respectively).

Angina pectoris returned in $32.4 \%$ of the patients studied. Univariate and multivariate (Cox) analysis did not show any difference among the IABP subgroups in the recurrence of angina.

\section{DISCUSSION}

In recent years, with the enormous growth of interventional cardiology, many patients have been referred for CABG at the end stage of their disease, with an ischemic myocardium and energy-depleted heart. Therefore, shortterm preoperative cardiac circulatory support with an IABP might be required. Although a consensus exists regarding IABP use in patients with cardiogenic shock and unstable conditions after an acute evolving MI, controversy remains regarding the routine use of IABP for other subgroups of high-risk patients. ${ }^{13}$ A recently published meta-analysis of 4 randomized controlled trials and 6 cohort studies of 1034 patients supported the preoperative use of IABP in high-risk patients. ${ }^{14}$ Most studies reporting the results of preoperative IABP support for CABG patients have been small, single-center, retrospective reports without long-term follow-up. The only studies containing larger numbers of patients have been multicenter studies with a relatively small number of patients recruited from each center, ${ }^{15}$ only 1 of which described the midterm results. ${ }^{3}$

The cohort of patients described in the present report was large $(\mathrm{n}=215)$ and included relatively high-risk patients (mean additive EuroSCORE, $12 \pm 3$ ). All patients required emergency surgery, and $18(8.3 \%)$ were in cardiogenic shock preoperatively. The actual early postoperative mortality in each of the IABP subgroups and the entire cohort was lower than the logistic EuroSCORE calculated mortality $(12.6 \%$ and $32.8 \%$, respectively). The operative mortality in the cardiogenic shock subgroup was lower than that described in the Cardiogenic Shock trial. ${ }^{16}$ It was about one half of the EuroSCORE expected mortality $(22.2 \%$ vs $43.5 \%)$. Older age, a prolonged CPB time, and fewer bypass grafts were associated with an increased risk of operative mortality (multivariate logistic regression analysis). In contrast to the cited series that concentrated on early postoperative results, our series also included detailed long-term ( $\leq 15$ years) postoperative follow-up data.

An important finding of our study was that the adjusted overall (early and late) survival and MACE- and MACCE-free survival of the different IABP subgroups (including the cardiogenic shock and acute MI subgroups) was similar. Cox analyses showed that PVD, OPCAB, advanced age, longer CPB time, female gender, and fewer bypass grafts were associated with decreased survival. OP$\mathrm{CAB}$ and longer $\mathrm{CPB}$ time were predictors of shorter MACE- and MACCE-free survival.

\section{CPB Time}

In our experience (including the patients in the present study), a prolonged CPB time will not relate necessarily to the number of bypass grafts performed but rather to the increased time needed to wean from CPB.

Previous studies have reported a prolonged CPB time to be a risk factor for early and late mortality. ${ }^{17}$ Our results support this observation and showed that a prolonged $\mathrm{CPB}$ time was an independent predictor of early and overall mortality. A prolonged CPB time was also associated with an increased occurrence of MACE and MACCE.

\section{OPCAB Surgery}

Displacement of the heart during OPCAB has often been associated with hemodynamic deterioration, especially when grafting the marginal branches of the circumflex coronary artery and the left ventricular branch of the right coronary artery, which sometimes barely emerges from the atrioventricular groove. Elective preoperative insertion of an IABP has appeared to facilitate intraoperative management of these vessels by reducing the hemodynamic instability associated with positioning of the heart. ${ }^{18}$

The OPCAB preferred approach was adopted in our center in 1999, the middle of the present study period, and was, therefore, the main indication for OPCAB use in the patients with IABPs included in our study.

Our study results have negated a previously published study suggesting better outcomes for high-risk OPCAB patients who were compared with high-risk on-pump patients. ${ }^{19}$ Our study included 53 IABP-supported OPCAB patients; these patients had significantly greater early mortality than the 162 IABP-supported patients who underwent $\mathrm{CPB}$. The OPCAB patients in our series had lower actuarial (Kaplan Meier) 10 -year survival $(24 \% \pm 6 \%$ vs $57 \% \pm$ $4 \% ; P<.001)$. Moreover, OPCAB was an independent predictor of decreased overall (early and late) survival and decreased MACE- and MACCE-free survival (Cox model). The decreased long-term patency rates of anastomoses performed on a beating heart and less complete revascularization could explain the inferior early and late outcomes of the OPCAB patients. ${ }^{19,20}$ The fact that the number of bypass grafts was included in the Cox model suggests that the poor outcomes of the OPCAB patients in our report were independent of the completeness of the revascularization and the number of grafts performed on the beating heart. 
Age

Multivariate analysis in our study revealed that increased age was associated with in-hospital and overall (early plus late) mortality. In addition, the occurrence of early unfavorable events (the sum of perioperative MI, cerebral infarct, deep sternal infection, IABP-related vascular complication, the need for revision, and death) was greater for patients $\geq 70$ years old. These findings in the preoperative IABPsupported patients are in concordance with previously published analyses of early and late results after $\mathrm{CABG} .{ }^{8} \mathrm{Age}$ is among the most important factors affecting early mortality and morbidity in the most recent Society of Thoracic Surgeons risk model. ${ }^{12}$

\section{Number of Bypass Grafts}

An increased number of bypass grafts in our group of IABP-supported patients was associated with decreased in-hospital mortality (multivariate logistic regression analysis). The patients with fewer grafts also had decreased adjusted long-term survival (Cox model). The decreased survival of patients with a lower number of bypass grafts could have been related to the presence of more diffuse disease, limiting the number of grafts that could be done. It could also have been related to incomplete revascularization.

These results support the well-established idea that providing complete revascularization during CABG will improve early and long-term survival. However, our results negate those of a large-scale, recently published report that has suggested that in the presence of a left internal mammary artery to left anterior descending artery anastomosis, reasonable incomplete revascularization of the circumflex and right coronary artery territories will not adversely affect early or long-term survival. ${ }^{21}$ A possible explanation for this discrepancy might be the difference between the 2 studies in the prevalence of high-risk patients and emergency cases. The achievement of complete revascularization in these high-risk patients with energy-depleted hearts might be more influential on the early and longterm results; however, long-term survival is also likely affected by the better patency rate of the BITA grafts used for grafting in $40 \%$ of the patients in our study. ${ }^{22}$

We recommend the use of BITA grafts for IABPsupported patients to all surgeons experienced with this grafting technique. A part of the reason that BITA patients did better (in addition to selection bias and the benefits directly related to the conduits) was probably because our cardiac surgical unit has routinely used BITA grafting for CABG (ie, facile with the use of BITA grafts in general).

\section{Peripheral Vascular Disease}

In a large multicenter study of 16,909 IABP-supported patients, balloon-related complications (major limb ischemia, severe bleeding, balloon leakage, and death) occurred in $2.6 \%$ of the patients, and PVD was an independent predictor of balloon-related complications. ${ }^{23}$

In our study, 42 patients $(19.5 \%)$ had PVD. IABP-related vascular complications occurred among $14.3 \%$ (vs $4 \%$ in non-PVD patients; $P=.023$ ), leading to an increased hospital stay (21.2 vs 11.8 days in patients without PVD; $P=.001$ ) and decreased 10-year survival (Kaplan-Meier, $21.4 \% \pm 6.3 \%$ ). Moreover, Cox analysis showed PVD to be associated with increased overall mortality and MACCE (Table 5).

\section{Study Limitations}

First, ours was a retrospective observational cohort study, and many of the identified factors could have been affected by selection bias. The number of bypass grafts was protective. The greatest difference in survival was observed between the use of 1 and 2 grafts (Figure 3). The observed difference could have resulted from other factors such as the quality of the distal vessels or "graft-ability." The same argument applies to the observed benefit of BITA grafting and the observed harm of OPCAB.

Second, we used an old registry (1996 to 2001) that had been coded according to EuroSCORE I. Our data were not coded using a method that enabled calculation of EuroSCORE II or the Society of Thoracic Surgeons score. Our study compared the patients' observed morality with the logistic EuroSCORE I calculated mortality, which probably overestimated the mortality. With more modern calculators, the difference between the observed and calculated morality might not be as large, and, in some subgroups, the observed morality might even be greater than the predicted morality.

Third, owing to the retrospective nature of the present study, several potential advantages of preoperative IABP insertion could not be addressed without comparing our patients to similar high-risk patients who were not supported preoperatively with IABP (control group).

Finally, despite the use of multivariate methods, residual confounders could have remained that were not included in the statistical analysis.

\section{CONCLUSIONS}

Our study has described the early and long-term outcomes of 215 consecutive preoperatively IABP-supported CABG patients treated during a 6-year period. The actual early postoperative mortality observed in each of the IABP subgroups was remarkably lower than the logistic EuroSCORE calculated mortality. These good early postoperative outcomes might have been related to the preoperative insertion of an IABP. In patients supported preoperatively with an IABP, better early and long-term results were strongly related to a younger age, shorter CPB time, and greater number of bypass grafts. We do not recommend avoiding the use of $\mathrm{CPB}$ (OPCAB) owing to 
the significant decrease in overall survival and the increased occurrence of MACE and MACCE in our OPCAB patients.

\section{References}

1. Lavana JD, Fraser JF, Smith SE, Drake I, Tesar Mullany DV. Influence of timing of intraaortic balloon placement in cardiac surgical patients. J Thorac Cardiovasc Surg. 2010;140:80-5.

2. Marra C, De Santo LS, Amarelli C, Della Corte A, Onorati F, Torella M, et al. Coronary artery bypass grafting in patients with severe left ventricular dysfunction: a prospective randomized study on the timing of perioperative intraaortic balloon pump support. Int J Artif Organs. 2002;25:141-6.

3. Holman W, Qing L, Kiefe C, McGiffin DC, Peterson ED, Allman RM, et al. Prophylactic value of preincision intra-aortic balloon pump: analysis of a state-wide experience. J Thorac Cardiovasc Surg. 2000;120:1112-9.

4. Christenson JT, Cohen M, Ferguson JJ III, Freedman RJ, Miller MF, Ohman EM, et al. Trends in intraaortic balloon counterpulsation complications and outcomes in cardiac surgery. Ann Thorac Surg. 2002;74:1086-90.

5. Onorati F, Impiombato B, Ferraro A, Comi MC, Spaccarotella C, Indolfi C, et al. Transbrachial intraaortic balloon pumping in severe peripheral atherosclerosis. Ann Thorac Surg. 2007;84:264-6.

6. Onorati F, Cristodoro L, Mastroroberto P, di Virgilio A, Esposito A, Bilotta M, et al. Should we discontinue intraaortic balloon during cardioplegic arrest? Splanchnic function results of a prospective randomized trial. Ann Thorac Surg. 2005;80:2221-8.

7. Roques F, Michel P, Goldstone AR, Nashef SA. The logistic EuroSCORE. Eur Heart J. 2003;118:882-3

8. Pevni D, Uretzky G, Mohr A, Braunstein R, Kramer A, Paz Y, et al. Routine use of bilateral skeletonized internal thoracic artery grafting: long-term results. Circulation. 2008;12:705-12.

9. Sabik JF III, Blackstone H. Coronary artery bypass graft patency and competitive flow. J Am Coll Cardiol. 2008;51:126-8.

10. Pevni D, Hertz I, Medalion B, Kramer A, Paz Y, Uretzky G, et al. Angiographic evidence for reduced graft patency due to competitive flow in composite arterial T-grafts. J Thorac Cardiovasc Surg. 2007;133:1220-5.

11. Radford MJ, Arnold JM, Bennett SJ, Cinquegrani MP, Cleland JG, Havranek EP, et al. ACC/AHA key data elements and definitions for measuring the clinical management and outcomes of patients with chronic heart failure: a report of the American College of Cardiology/American Heart Association Task Force on Clinical Data Standards (Writing Committee to Develop Heart Failure Clinical Data Standards): developed in collaboration with the American College of Chest Physicians and the International Society for Heart and Lung Transplanta- tion: endorsed by the Heart Failure Society of America. Circulation. 2005;112 $1888-916$

12. Shahian DM, O'Brien SM, Filardo G, Ferraris VA, Haan CK, Rich JB, et al., for the Society of Thoracic Surgeons Quality Measurement Task Force. The Society of Thoracic Surgeons 2008 cardiac surgery risk models: part 1—coronary artery bypass grafting surgery. Ann Thorac Surg. 2009;88:S2-22.

13. Baskett RJ, O'Connor GT, Hirsch GM, Ghali WA, Sabadosa KA, Morton JR, et al. The preoperative intraaortic balloon pump in coronary bypass surgery: a lack of evidence of effectiveness. Am Heart J. 2005;150:1122-7.

14. Etienne PY, Papadatos S, Glineur D, Mairy Y, El Khoury E, Noirhomme P, et al Reduced mortality in high-risk coronary patients operated off pump with preoperative intraaortic balloon counterpulsation. Ann Thorac Surg. 2007;84:498-502.

15. Baskett RJ, O'Connor GT, Hirsch GM, Ghali WA, Sabadosa K, Morton JR, et al for the Northern New England Cardiovascular Disease Study Group. A multicenter comparison of intraaortic balloon pump utilization in isolated coronary artery bypass graft surgery. Ann Thorac Surg. 2003;76:1988-92.

16. Hochman JS, Sleeper LA, Webb JG, Sanborn TA, White HD, Talley JD, et al Early revascularization in acute myocardial infarction complicated by cardiogenic shock. N Engl J Med. 1999;341:625-34.

17. Onorati F, De Feo M, Mastroroberto P, Cristodoro L, Pezzo F, Renzulli A, et al Determinants and prognosis of myocardial damage after coronary artery bypass grafting. Ann Thorac Surg. 2005;79:837-45.

18. Suzuki T, Okabe M, Handa M, Yasuda F, Miyake Y. Usefulness of preoperative intraaortic balloon pump therapy during off-pump coronary artery bypass grafting in high-risk patients. Ann Thorac Surg. 2004;77:2056-9.

19. Lim E, Drain A, Davies W, Edmonds L, Rosengard BR. A systematic review of randomized trials comparing revascularization rate and graft patency of off-pump and conventional coronary surgery. J Thorac Cardiovasc Surg. 2006;132: 1409-13.

20. Takagi H, Manabe H, Umemoto T. Late mortality in off-pump versus on-pump coronary artery bypass grafting: a meta-analysis of propensity score-adjusted studies. J Thorac Cardiovasc Surg. 2011;142:475-7.

21. Rastan AJ, Walther T, Falk V, Kempfert J, Merk D, Lehmann S, et al. Does reasonable incomplete surgical revascularization affect early or long-term survival in patients with multivessel coronary artery disease receiving left internal mammary artery bypass to left anterior descending artery? Circulation. 2009; 120:S70-7.

22. Tatoulis J, Buxton BF, Fuller JA. Patencies of 2127 arterial to coronary conduits over 15 years. Ann Thorac Surg. 2004;77:93-101.

23. Ferguson JJ III, Cohen M, Freedman RJ Jr, Stone GW, Miller MF, Joseph DL, et al. The current practice of intra-aortic balloon counterpulsation: results from the Benchmark Registry. J Am Coll Cardiol. 2001;38:1456-62. 